\title{
Impact of legal adjustments of selected countries on logistics of enterprises in the field of transport and forwarding
}

\author{
Alena Vavrova ${ }^{1}$, Daniela Spirkova ${ }^{2}$ and Dagmar Caganova ${ }^{2}$ \\ ${ }^{1}$ Institute of Management, Slovak University of Technology in Bratislava \\ Vazovova 5, 81243 Bratislava \\ (alena.vavrova@stuba.sk) \\ ${ }^{2}$ Institute of Management, Slovak University of Technology in Bratislava \\ Vazovova 5, 81243 Bratislava \\ (daniela.spirkova@stuba.sk) \\ ${ }^{3}$ Faculty of Materials Science and Technology in Trnava \\ Slovak University of Technology in Bratislava \\ Vazovova 5, 81243 Bratislava \\ (dagmar.caganovaestuba.sk)
}

\begin{abstract}
The article is devoted to the influence of logistics on small-sized and middle-sized enterprises on transport and shipping and the influence of the European norms and national legislation on the process of undertaking in this area. Paper provides the review of contemporary issues in the field of logistics, transport, and forwarding; describes the state and development of small-sized and middle-sized enterprises in Slovakia and in selected EU countries. Authors in the paper also analyze the influence of logistics on small-sized and middlesized enterprises from the view of European and national legislation in the selected countries.
\end{abstract}

Keywords: logistics, road haulage, forwarding, EU countries

\section{Introduction}

Logistics is likely understood by couple of approaches whereby its developmental phases progressively change. The importance of logistic is growing along with increasing globalization. All companies are exposed to strong competitive preassure, and in this situation logistic plays a strategic role [10]. Logistics constitutes scientific discipline implying processes of effective planning, efficient stream and storage, realisation, organization and controlling It includes two basic aspects namely defining infrastructure and activities supervision. The aspect focused on infrastructure constitutes material-technological basis, technical equipment and technologies. It is possible to declare that storehouses, storage technologies, transport vehicles, handling devices etc. belong there. The aspect focused on managing constitutes communication, information, decision-making and controlling processes. Logistic technology base on the interaction of among the various subsystems of the logistic 
chain [11]. Business logistics is overall occupied with all kinds of motion-store based activities allowing flow of material, products and services [1]. Based on Brezina, Čičková and Reiff [2] the logistics implmentation in business enables proccess optimalization of materials assecuration, their storage realization, shipment and all connected activities. Unsubstitutable role on the present has the information part of logistics. Its main goal is to provide complex information not only about quality and quantity but also about destination, way and use of transport and also about other attributes of the logistic process.

One of the logistic systems most important factors with fundamental influence on logistics costs increase and decrease is the road transportation. For its high flexibility and adaptability it is absolutely most utilized transport [3]. According to the fact that road transportation is the most used for goods transport roads become overloaded and destroyed. For goods shipping by road truck transport are used mainly vehicles with lump gross weight over 3.5 tons. At the present in the European Union there is registered almost one vehicle onto two inhabitants and road truck transportation constitutes two thirds from the whole tonnage [3].

The goods export or import in international truck freight transportation influence forwarding agent or transport operator by legislative provisions of particular countries which have to be accomplished. Very important determinant in international truck road transportation are price, quality and time. This means undamaged goods delivery on time under minimum freight costs.

\section{Materials and Methods}

In the paper there were used statistical data and analyses done by Eurostat, World Bank and the Statistical Office of the Slovak Republic. Further there were analyzed the selected laws and standards of the Slovak Republic, documents and regulations of the Ministry of Transport of the Slovak Republic. We analyzed a number of standards, legislative norms on international road haulage business entities, related to the logistics issues of selected EU countries such as Regulation EC 715/2007 of the European Parliament and of the Council and the emission classes, Directives 2003/37/ EC and 2007/46/ EC of the European Parliament and of the Council, etc.

For investigating the issue of logistic, we used a combination of several scientific methods, approaches (particularly analysis, abstraction, synthesis, induction, deduction, comparison), which allowed mutually coherent knowledge of the facts and investigation processes in all their complexity.

\section{Logistic performance index (LPI)}

The logistic approach in small and medium firms operating in transport and shipment area influences process of satiation of customer wants and complex services assurance. Logistics becomes the most evolving segment and offer an open space for innovation and continuous improvement[12]. Logistic Performance Index (LPI) [4] can clarify the possibility to compare logistic condition and level on the worldwide 
basis or logistic level of the Slovak republic in comparison with chosen countries. Logistic Performance Index is based on World Bank data processing coming from over one thousand managers (global forwarders and express carriers) with intention to help particular countries with bidding identification and opportunities. It allows comparison in 160 countries in term of business volume, customs disposal performance, infrastructure quality and shipment delivery time. It also merges detailed knowledge about particular countries and so enables to analyze worldwide logistics stage.

LPI consists from quality and quantity evaluations and helps to create profiles of particular countries within the frame of logistic processes. It measures performance within the country logistic process and offers two different views on international and domestic market. Ranking data come from specialist's research in logistics area. It is built up by weighted average and verifies logistic performance of a particular country in six areas:

1. Customs area - focused on effectiveness, quality and level of customs clearance,

2. Infrastructure - transport and business infrastructure quality,

3. Shipments - competitive prices achievements, organization,

4. Logistics competence - logistic services quality and proficiency,

5. Shipments monitoring and tracking,

6. Delivery time - time allowances - frequency or period in which shipment reaches the receiver in adjusted time or in expected period.

World Bank [5] published first research subject's data in 2007, later in 2010 and since then executes and publishes them regularly in two years period.

Table. 1. World Ranking of Selected Countries by LPI for 2016

\begin{tabular}{|c|l|r|r|r|r|r|r|r|}
\hline $\mathbf{2 0 1 6}$ & \multicolumn{1}{|c|}{ Country } & LPI & $\begin{array}{c}\text { Customs } \\
\text { area }\end{array}$ & Infrastructure & Shipments & $\begin{array}{c}\text { Logistics } \\
\text { Competence }\end{array}$ & $\begin{array}{c}\text { Monitoring and } \\
\text { tracking } \\
\text { of shipments }\end{array}$ & $\begin{array}{c}\text { Delivery } \\
\text { time }\end{array}$ \\
\hline $\mathbf{1}$ & Germany & $\mathbf{4 , 2 3}$ & 4.12 & 4.44 & 3.86 & 4.28 & 4.27 & 4.45 \\
\hline $\mathbf{7}$ & Austria & $\mathbf{4 , 1 0}$ & 3.79 & 4.08 & 3.85 & 4.18 & 4.36 & 4.37 \\
\hline $\mathbf{8}$ & Great Britain & $\mathbf{4 . 0 7}$ & 3.98 & 4.21 & 3.77 & 4.05 & 4.13 & 4.33 \\
\hline $\mathbf{1 6}$ & France & $\mathbf{3 . 9 0}$ & 3.71 & 4.01 & 3.64 & 3.82 & 4.02 & 4.25 \\
\hline $\mathbf{2 1}$ & Italy & $\mathbf{3 . 7 6}$ & 3.45 & 3.79 & 3.65 & 3.77 & 3.86 & 4.03 \\
\hline $\mathbf{2 6}$ & Czech Republic & $\mathbf{3 . 6 7}$ & 3.58 & 3.36 & 3.65 & 3.65 & 3.84 & 3.94 \\
\hline $\mathbf{4 1}$ & Slovak Republic & $\mathbf{3 . 3 4}$ & 3.28 & 3.24 & 3.41 & 3.12 & 3.12 & 3.81 \\
\hline
\end{tabular}

Source: Vavrova, 2017 [6]

As the order of selected countries in the world rankings of the LPI rises, the rating of the analyzed areas also rises. Compared to former years in the year 2016, Germany maintained its position as the leader (Table 1). Austria strengthened by 15 seats, the Czech Republic with 6 seats. The quality and level of infrastructure, the achievement of competitive prices and quality of logistics services as well as the tracking of shipments have caused the Slovak Republic to move upwards from the previous period. The United Kingdom, France and Italy did not defend their positions against 
the previous period due to the positive development of logistics in other countries, despite the fact that they strengthen de facto in the key areas.

\section{Legal Adjustments Impact of Selected Countries on the Logistics of Small and Medium-sized Enterprises in the Field of Transport and Forwarding}

Driving business activities in the field of road freight transport and forwarding on the territory of the Slovak Republic is not easy. For the operation of road freight transport, a Community license and license must be obtained and specific conditions fulfilled. At the minimum cost, purchasers are required to deliver the goods as quickly as possible to their destination. In international road freight transport, the transport contract is concluded under the CMR Convention. When performing road freight transport, the AETR agreement on the work of car crews must be observed.

The level of the minimum wage in the selected member countries is considerably affected by the economy of businesses in the area in question, the tolls for the use of roads in the EURO VI emission class and the number of axles 4 and more and the average price of the euro expressed in euro (Table 2).

Table. 2. Amount of hourly minimum wage, cost of fuel, and tolls in selected EU countries

\begin{tabular}{|l|c|c|c|}
\hline \multicolumn{1}{|c|}{ Country } & $\begin{array}{c}\text { Hourly Amount of } \\
\text { Minimum Wage } \\
\text { (in } € \text { ) }\end{array}$ & $\begin{array}{c}\text { Fuel Price } \\
\text { (in } € \text { ) }\end{array}$ & $\begin{array}{c}\text { Toll Fees for EURO VI } \\
\text { Emission Class and Axles } \\
\text { Number 4 and more (in } € \text { / km) }\end{array}$ \\
\hline Germany & 8.84 & 1.166 & 0.117 \\
\hline Austria & 8.49 & 1.104 & 0.3743 (day) / 0.3755(night) \\
\hline France & 9.76 & 1.262 & $\begin{array}{c}\text { The fee depends on a specific } \\
\text { section (toll gates) }\end{array}$ \\
\hline Italy & 6.30 & 1.431 & $\begin{array}{c}\text { The fee depends on the particular } \\
\text { section (toll gates) }\end{array}$ \\
\hline Great Britain & 8.20 & 1.370 & $\begin{array}{c}\text { The fee depends on a particular } \\
\text { section (toll gates) }\end{array}$ \\
\hline Czech Republic & 2.52 & 1.120 & 4.12 / 5.88 (Friday 15:00 - 20:00) \\
\hline Slovak Republic & 2.50 & 1.137 & 0.188 \\
\hline
\end{tabular}

Source: Vavrova, 2017 [6]

The basic legislative attributes affecting the logistics of small and medium-sized enterprises in the field of transport and forwarding are the following in the selected countries.

Germany. By virtue of the Law on the Minimum General Minimum Wage (Gesetz zur Regelung eines allgemeinen Mindestlohns (Mindestlohngesetz - MiLoG)) (the 
Minimum Wage Law) of the Federal Republic of Germany with effect from 1 January 2015, each employee is entitled to a minimum wage of EUR 8.50 For the hour worked. From 1 January 2017, this amount was adjusted to EUR 8.84 per hour. This law applies to all employees who carry out work in the territory of Germany, irrespective of the nationality of the employer or the type of employment. In practice, this means that if the Slovak employer carries out the freight transport of goods by road to Germany, the wage that must be awarded to the driver of a lorry corresponds to the approved minimum wage in Germany. The minimum wage law also provides for the payment of the minimum wage, which must be paid at the agreed time, but at the latest on the last day of the month following the month in which the work was done. For non-compliance with the Minimum Wage Act, Failure to pay wages at all or failure to pay this salary in time impose a penalty on the employer up to EUR 30,000. A temporary exception to this law is so far granted if it is so-called "Net transit" for drivers of goods transporting goods through the territory of Germany to another country, that the loading or unloading of goods in the territory of Germany or the cabotage transport carried out shall not be carried out. Minimum wage does not include contributions to the cost of living, diets, meals, timeless hours, Sundays and holidays, Christmas and holiday allowances.

Other attributes that affect the cost of transporting goods are road and motorway charges. The toll rates for trucks for the use of the kilometer of the transport infrastructure in Germany are graded according to the vehicle's emission class and the number of axles of the vehicle. The lowest rate is EURO VI [7] for any number of axles. To pay the toll, an On-Board Unit (OBU) installation is required and German toll is not subject to VAT.

The current legislation applied in Germany is a ban on spending weekly rest, 45 hours in the vehicle with effect from 25.5.2017. Compulsory rest should be spent by the driver of the truck in accommodation facilities or at the headquarters of the company.

Austria. The same principle of compliance with the statutory minimum wage as in Germany was introduced from 1.1.2017 also in Austria. The minimum wage in Austria is EUR 8.49 per hour. The obligation to electronically report employees working in Austria through an electronic form has each employer in advance. Penalties for failure to report, eventual violation of other obligations associated with the retention of documents may be claimed up to $€ 10,000$.

For vehicles with a maximum permissible weight of more than 3.5 tonnes, the toll rates in Austria are set according to the number of axles, emission class and whether the driving is done day or night. The rate of charge therefore includes the basic rate per kilometer including air pollution (emission class) and noise tax (day or night). From the air pollution surcharge, all vehicles with a maximum permissible weight of over 3.5 tonnes in the EURO VI emission class 2, 3, 4 and above are exempt and therefore the lowest charges for the use of road infrastructure in road freight transport are the use of motor vehicles EURO VI emission class during daytime driving. For commercial vehicles of categories N1, N2, N3 [8] and EURO 0 and EURO 1 emission class seals, the entry into Vienna and certain parts Lower Austria and from 1.1.2016, this ban has also been extended to EURO 2 emission vehicles and semitrailers. Furthermore, drivers in Lower Austria and Vienna are obliged to designate vehicles and semi-trailers. Low emission plaques indicating that vehicles do not fall 
under the EURO 0-2 emission class covered by the ban on entry. The plaques are color-coded according to the EURO 1 emission classes - black, 2 - red, 3 - yellow, 4 green, 5 - blue, 6 - purple. This obligation applies to owners of commercial vehicles and semi-trailers from 1.1.2015. The price for the plaque is $€ 25$ without VAT. A socalled "toll" GO - Boxes resp. On-board unit. Charges are levied through Go-boxes or toll portals. When Go Goes, it communicates through microwaves with toll gates. Austrian toll is subject to VAT.

France. Another country in the European Union that introduced the Minimum Wage Act (Loi Macron) with conditions comparable to those in Germany and Austria is France. The employer is obliged to pay a minimum wage to the employee at a fixed rate if France is the destination or When loaded with goods including cabotage. The exception applies only to transit. Since January 1, 2017, the minimum wage has been increased from 9.67 euros to 9.77 euros per hour, and there has also been a change in the fact that road hauliers, in addition to wage and freight documents, have to fill in on the Ministry of Labor's on-line website In France, the so- Attestation de détachment resp. A confirmation of posting, which must be in French, and a copy in the case of a check also available in the vehicle. The certificate is valid for 18 months. If the driver does not have this certificate or if it is incorrectly filled, he / she may be penalized up to 750 euros. In the absence of a contract of employment, the amount of the fine may be up to EUR 450. It is also the responsibility of the carrier to designate a contact person in

Charges for the use of motorways are not collected by electronic toll, but specific sections are charged. Trucks are required to install the TIS-PL on-board unit. The toll rate is subject to VAT. The highest tariff, of course, includes trucks without regard to the emission class. The size of the tariff is dependent on the passing section and the specified classification. Classification 1 consists of passenger cars, 2 - caravans, 3 buses, 4 - trucks and 5 - motorcycles.

France who is authorized to communicate with the authorities. If these conditions are met, the amount of the sanction granted may be up to $€ 2,000$ per employee. In case of a repeated offense, the amount is up to 4000 euros. Due to the efforts of the French authorities to ensure a cleaner environment, Eco-zones and entry into them are only allowed with a valid emission plaque. In the case of transport to places such as Paris, Lyon and Grenoble, it is necessary to equip the motor vehicle with the Crit'Air emission plate available in 6 categories. At present, it is possible to enter all ecological zones. The null category - green represents the so- Elektromobily resp. Zero emission vehicles. First category purple for EURO 6 and 5 gasoline engines, year of production since 2011, second yellow category for EURO 4 gasoline, production year 2006 - 2010 and EURO 5 and 6 diesel engine, year of production since 2011, third orange category for vehicles EURO 2 and 3, production year 19972005 for petrol engines and EURO 4 diesel engines with year of production 2006 2010, fourth category dark purple for diesel engines EURO 3 with production year 2001 - 2005 and last market category black for diesel vehicles EURO 2 with production year 1997-2000.

Italy. As in the case of the previous countries of the European Union, Italy is also one of the countries from 27 December 2016 where comparable conditions will apply 
as in the case of France, Germany and Austria for the posting of staff abroad for the performance of international road haulage. So far, legislation is only valid for cabotage transport. The introduction of this law is based on the LoiMacron French law and, therefore, the conditions are comparable to French law. In addition to complying with the minimum wage, delegation of a representative in Italy and compliance with other social regulations will also be required. Delegation of a representative is not yet required. From July 2017, the legislation in force should enter into force and apply, in addition to cabotage, to the transport of goods carried out in Italy. The minimum wage is EUR 6.30. The law will not apply to transit, but the other provisions of the law will apply as in Germany, Austria and France to cabotage and the loading and unloading of goods in Italy. For these shipments, a message must be sent at least 24 hours prior to the start of transport or cabotage on Italian territory on the prescribed Italian language form, indicating the date of commencement and completion o The reimbursement of charges for the use of road infrastructure in Italy depends on two classes. Class A specifies vehicles where the height of the vehicle is less than or equal to 1,3 meters measured from the first axle and Class B specifying the vehicle height or axle number where the height of the vehicle measured from the first axle is greater than $1,3 \mathrm{~m}$ and the number of axles of the vehicles Including trailers with 3, 4 and 5 or more axles. On Italian motorways of the Autostrade per l'Italia there are standardized signs indicating the payment for the use of specific sections of road infrastructure at the toll gates on entry and exit. Entry gates are marked with signs placed under gate entry or Telepass customers. Telepass is an onboard unit for electronic payment of usage fees highways. In the output so-called Gate exit is a layout of 5 types of tables placed so that you can clearly and immediately identify the payment option from a distance. The yellow background on the blackboard clearly indicates the possibility of payment by the Telepass boarding unit and therefore these gateways can only be used by the holders of this device. The blue color of the blackboard indicates that the payment method is possible by payment cards. The yellow "T" on the blue board indicates the possibility that the Telepass onboard unit can go through this gateway but can also be used by paying customers with a non-Telepass payment card. White cash-white charts indicate that a cash payment is accepted at the gate, and white pillars with a pictogram of the hand and cash indicate the presence of the operator. If a white card with a cash symbol in the bottom left is a blue card, payment in cash or a credit card is possible. Toll in Italy is subject to VAT.

Great Britain. The United Kingdom has not yet determined the condition for paying the minimum wage per hour in the country for employees from other countries. The hourly minimum wage is currently set at $£ 7.20$ in England, which is 8.20 euros per hour.

Fees for drivers of goods vehicles with a gross weight of over 3.5 tonnes are categorized according to the number of axles and height according to the first axle. Charged the stretch of road between Wolverhampton and M6 Birminahmom where the toll fee levied in two tariffs and the day or night fee. Fees for the use of highways for the vehicles specified price following sessions - Monday to Friday 6:00 to 11:00 p.m. hours at $11.00 \mathrm{lbs}$, Saturday and Sunday from 6:00 to 11:00 p.m. hours at 9.60 lbs and over the week at night 11:00 p.m. to 06:00 hours at $8.60 \mathrm{lbs}$ for class 4 where it belongs delivery truck or coach, class 5 is designed for trucks and for class 6 for 
vehicles with 6 or more axles. If the vehicle is marked "M6toll", the driver can save up to $5 \%$. M6toll is a label

Toll gates and is part of the national highway network and subject to transport regulations including speed limits. In addition, some parts of the M25, M48, M4, A15, Tamar, Mersey - Kingsway and Eurotunel tunnels are also charged. For trucks with a total weight of more than 12 tonnes, a toll system is introduced, with the price being based on the number of axles for the tractor - for 2, 3, 4 or more axles, plus a towing vehicle with a total weight of up to 4 tonnes with a trailer, It can be 2, 3, 4 or more.

The fee for the use of the ferry is for a truck (tractor + semi-trailer) of about 360 euros in two ways, and the amount of the Eurotunnel charge is about 500 euros bidirectionally. For both modes of transport from France to Great Britain and back, you must complete the form with the departure time

Czech Republic. As in the case of Great Britain and the Czech Republic, it is not yet necessary to pay a tax-deductible hourly minimum wage in the given country for foreign employer employees. The minimum wage is set at CZK 66, which is 2.52 euros. The amount of charges related to the use of road infrastructure in the Czech Republic by trucks with a total weight of over 3.5 tonnes depends on the type of road communication, Whether it is a highway or a high-speed way or a 1st class road, the number of axles and the EURO emission class. The lowest fee is EURO VI and EEV. An increased charge is for trucks in the Czech Republic on Friday between 15:00 and 20:00 hours. When using a highway or expressway on the EURO and the number of axles 4 or more, this fee is increased by almost $43 \%$. Therefore, carriers should consider transit through the Czech Republic on Fridays from 15:00 hours. The toll rate is not subject to VAT. It is necessary to install the on-board unit called " OBU (On-Board Unit). Payment can be made in two ways: post-pay - at a specified time based on actual mileage or pre-pay, when a certain amount of money is charged to the OBU, Kilometers deducted from the retired amount. For recharging tolls for trucks, the Czech Republic provides various discounts based on the total annual amount in CZK. That is, if the carrier pays more or 75,000 CZK for the use of the road infrastructure for the use of the road infrastructure, which amounts to approximately EUR 2,860, the Czech Republic will receive a refund of 5\%. If this amount is greater than or equal to $110,000 \mathrm{CZK}$ (approximately 4193 euros), the refund will be $8 \%$. For an amount greater than or equal to $190,000 \mathrm{CZK}$ (approximately 7246 euros), the discount is set at $11 \%$, and the amount of more than or equal to $300,000 \mathrm{CZK}$ (about 11436 euros) is $13 \%$.

Slovak Republic. The operation of a transport company is subject to Act No. 56/2012 Z.z., on Road Transport [9]. More than 3.5 tonnes of road freight traffic is required to meet all specific conditions and licenses. The most common legal form of transport business is a tradable or limited liability company, with the entrepreneur choosing any legal form of business subject to Slovak legislation. If an existing company is older than 15 months, it is necessary to prove the financial capacity on the basis of the financial statements for the previous period. In the case of a company that is not older than 15 months, the financial capacity is proved by the height or, respectively, by increasing the company's share capital according to the number of 
vehicles on the first vehicle in the order of EUR 9000 and for each additional vehicle of EUR 5000. There is another, but in the conditions of the Slovak Republic, an unrealistic possibility of proving the financial capacity, which is the bank guarantee, respectively. Liability insurance of a given carrier subject to a European Union regulation. Insurance companies, banks and other financial institutions are not willing to guarantee the creditworthiness of a transport company and are also not acceptable

Fees for the use of the transport infrastructure of motorways, express roads and 1st class roads in Slovakian conditions for trucks above 3,5 tons of total weight are determined according to the vehicle category, especially for trucks and especially for buses. Vehicle categories are further broken down by weight from 3.5 to 12 tonnes and over 12 tonnes according to the number of axles 2, 3, 4 and 5 and EURO 0 - II, EURO III and IV and EURO V, VI and EEV emission classes. The lowest toll rates are in our conditions for EURO V, VI and EEV emission classes.

\section{Conclusion}

Based on the analysis of the legislative norms of selected European Union countries on international road haulage business entities, we have come to the conclusion that European legislation transformed into national legislation has a direct economic impact on the logistics of transport and forwarding enterprises.

From the LPI point of view this is particularly the case for organizations and the achievement of competitive prices, logistical competence, expected delivery times and transport infrastructure. The shipping cost amount is derived from the charges that the carrier must pay or sender has to include into this price. Legislation affects pricing, especially in the area of strict adherence to the minimum wage for work performed in the territory of countries such as Germany, Austria and France. Similar legislation is also being drafted in Italy. Sending the lorry driver in international road freight to these countries requires more demanding preparation and fulfillment of the legislative conditions as well as the expertise of the transport and forwarding employees. Minimum wage regulations has a significant impact on the quality of logistics services and on the shipping expertise. The European AETR agreement on the crews of vehicles work in international road haulage has an impact on shipment delivery times. The quality of road transport infrastructure is closely related to the road user charges retrieval, toll. The toll charges amount as well as the method of payment vary depending on the country where the goods transport realizes, which can be considered as a negative economic moment. The toll rates are mainly affected by the vehicles category and EURO emission class.

\section{References}

1. Viestová, K., Štofilová, J. Oreský, M., Škarpa, R.: Lexikón logistiky. (Lexicon of logistics). Bratislava, EKONÓM, (2005).

2. Brezina, I, Čičková, Z.,Reiff, M.: Kvantitatívne metódy na podporu logistických procesov. (Quantitative methods to support logistics processes). Bratislava: EKONÓM, (2009). 
3. Zväz logistiky a zasielatel'stva: Odborné texty podl'a štandardu Medzinárodnej federácie zasielatel'ských zväzov, (2014).

4. Logistický výkonnostný index. Logistic performance index. Available on internet: http://lpi.worldbank.org/international

5. The World Bank - Global rankings 2007-2016. Available on internet: https://lpi.worldbank.org/international/global/2007-2016

6. Vavrová, A.: Impact of logistics on small and medium-sized enterprises in the field of transport and forwarding. Dissertation thesis, Slovak University of Technology in Bratislava, Slovakia, (2017).

7. Regulation EC $715 / 2007$ of the European Parliament and of the Council and the emission classes listed in subchapter 2.9, (2007).

8. Directives 2003/37 / EC and 2007/46 / EC of the European Parliament and of the Council (2003, 2007).

9. Zákon č. 56/2012 Z. z. o cestnej doprave. (Act No. 56/2012 Z.z., on Road Transport). Available on internet: http://www.epi.sk/zz/2012-56

10.Straka, M., Malindžáková, M., Trebuňa, P., Rosová, A., Pekarčíková, M., Fill, M.: Application of Extendsim for Improvement of production logistic efficiency.International Journal of Simulation Modeling 16(3),422-434 (2017).

11.Ferencová, J., Hurná, S.: Logistics technologies in aviation.Acta logistica4(2),11-17(2017)

12. Jurik, T.: Concept of service logistics. 3(2), 21-25 (2016). 